\title{
Escala de Identificação de Precocidade e Indicadores de Altas Habilidades/Superdotação (EIPIAHS): um instrumento em construção
}

\author{
Precocity Identification Scale and Indicators of Giftedness: an instrument \\ under construction
}

Escala de identificación de precocidad e indicadores de superdotación: un instrumento en construcción

\section{Bárbara Amaral Martins}

Professora doutora na Universidade Federal de Mato Grosso do Sul, Corumbá, Mato Grosso do Sul, Brasil. barbara.martins@ufms.br

ORCID - https://orcid.org/0000-0003-4278-1661

Recebido em 13 de agosto de 2020

Aprovado em 27 de outubro de 2020

Publicado em 25 de novembro de 2020

\section{RESUMO}

Estima-se que o fenômeno altas habilidades/superdotação esteja presente entre os indivíduos na mesma proporção em que está a deficiência intelectual. No entanto, os registros do Censo Escolar evidenciam a invisibilidade desse público em nossas escolas, a despeito das contribuições sociais que este pode vir a prestar. Estudantes com altas habilidades/superdotação precisam ser devidamente identificados para que as medidas educacionais necessárias ao máximo desenvolvimento de suas potencialidades possam ser tomadas. Assim, o objetivo desta pesquisa é avaliar os itens de uma escala de identificação de alunos precoces com indicadores de altas habilidades/superdotação no Ensino Fundamental I e verificar sua consistência. Sendo um instrumento destinado a professores, contamos com a participação de 28 docentes: 18 avaliaram cada um dos 75 itens da escala, e 10 aplicaram-na a uma amostra de 71 estudantes. A partir da coleta de opiniões e análises estatísticas, dez itens foram considerados pouco funcionais e, por isso, foram excluídos. Verificou-se, estatisticamente, que o instrumento apresenta fidedignidade. Novas análises são necessárias para a constatação de sua validade.

Palavras-chave: Educação Especial; altas habilidades/superdotação; instrumentos de mensuração.

\section{ABSTRACT}

It is estimated that the phenomenon of giftedness is present among individuals in the same proportion as the intellectual disability. However, the School Census records show the invisibility of this public in our schools, despite the social contributions that it may come to provide. Students with giftedness need to be properly identified so that the educational measures necessary for the maximum development of their potential can be taken. Thus, the objective of this research is to evaluate the items of a scale of identification of precocious students with indicators of giftedness in Primary School and to verify their consistency. As an 
http://dx.doi.org/10.5902/1984686X34664

instrument for teachers, we have the participation of 28 teachers, 18 evaluated each of the 75 items on the scale and 10 applied it to a sample of 71 students. From the collection of opinions and statistical analysis, ten items were considered to be ineffective and therefore excluded. It was statistically verified that the instrument is reliable. Further analysis is necessary to verify its validity.

Keywords: Special Education; giftedness; mensuration instruments.

\section{RESUMEN}

Se estima que el fenómeno de superdotación se presenta entre los individuos en la misma proporción que la discapacidad intelectual. Sin embargo, los registros del Censo Escolar muestran la invisibilidad de este público en nuestras escuelas, a pesar de los aportes sociales que pueda llegar a aportar. Los estudiantes con superdotación deben estar debidamente identificados para que se puedan tomar las medidas educativas necesarias para el máximo desarrollo de su potencial. Así, el objetivo de esta investigación es evaluar los ítems de una escala de identificación de alumnos precoces con indicadores de superdotación en la Escuela Primaria y verificar su consistencia. Como se trata de un instrumento para los docentes, contamos con la participación de 28 docentes, 18 evaluaron cada uno de los 75 ítems de la escala y 10 lo aplicaron a una muestra de 71 alumnos. A partir de la recogida de opiniones y análisis estadístico, diez ítems se consideraron ineficaces y por tanto han sido excluidos. Se verificó estadísticamente que el instrumento es confiable. Es necesario un análisis más detallado para verificar su validez.

Palabras clave: Educación Especial; superdotación; instrumentos de medición.

\section{Introdução}

O público da Educação Especial é composto por estudantes com deficiência, transtornos globais do desenvolvimento e altas habilidades/superdotação. As altas habilidades/superdotação (AH/SD), especificamente, constituem um fenômeno resultante da combinação de fatores de ordem biológica, pedagógica, psicológica e psicossocial (PRIETO SÁNCHEZ; FERRANDO, 2016) e correspondem ao foco central desta pesquisa, que tem por objetivo principal avaliar os itens de uma escala de identificação de alunos precoces com indicadores de altas habilidades/superdotação e verificar sua consistência.

O desenvolvimento pleno das potencialidades dos indivíduos com AH/SD está atrelado às condições ambientais disponíveis, significando que o contexto educacional deve ser estimulante e desafiador. Porém, nota-se que, levando-se em consideração as estimativas de incidência do fenômeno na população geral, o registro desse público nos cadastros censitários é baixo (BARRETO; METTRAU, 2011) - um reflexo da invisibilidade desses estudantes em sala de aula.

Pérez e Freitas (2011) consideram que um dos principais problemas da invisibilidade desses estudantes é a ausência de formação docente, pois os cursos de Pedagogia e 
http://dx.doi.org/10.5902/1984686X34664

demais licenciaturas nem sempre abordam a temática, sequer com o aprofundamento devido, o que também ocorre nos cursos de Educação Inclusiva ou Educação Especial, os quais tendem a priorizar o estudo das deficiências. Essas afirmações tornam-se nítidas diante do resultado da análise do material "Educação Inclusiva: Incluir na Diversidade", programa de capacitação com 40 horas, oferecido pelo Ministério da Educação (MEC) para gestores e professores, no qual as autoras aludidas localizaram apenas três menções ao termo AH/SD ao longo de suas 266 páginas.

Esses resultados convergem com os dados da pesquisa realizada por Martins, Chacon e Almeida (2020), que, ao compararem a formação inicial de professores sobre $\mathrm{AH} / \mathrm{SD}$ em duas universidades públicas, uma brasileira e outra portuguesa, constataram que o estudo desta temática é abordado superficialmente e está relacionado ao interesse e envolvimento científico dos docentes dos cursos.

Nessa perspectiva, chama a atenção o fato de não serem somente os professores de sala regular que apresentam conhecimentos insuficientes acerca desse público, mas, inclusive, alguns professores reconhecidos como especializados. Cruz (2014) conduziu um estudo junto a dez professores atuantes no Atendimento Educacional Especializado (AEE) para AH/SD em municípios da Grande Vitória-ES, com o intuito de analisar suas concepções sobre AH/SD. Os dados foram coletados por meio de grupo focal, e, após a análise dos discursos, a autora constatou que esses profissionais não possuíam uma definição clara sobre esses estudantes em razão do baixo aparato teórico, uma vez que eles expunham suas opiniões, mas não as fundamentavam. A imprecisão ao definir o que são $A H / S D$ e quem são os estudantes que as apresentam resultava em incertezas e dificuldades para identificá-los. Cruz (2014) ressalta que, durante muito tempo, se utilizou exclusivamente o "Guia de observação" proposto por Guenther (2006) para a identificação e o encaminhamento ao AEE no estado de Espírito Santo. Contudo, o referido instrumento não tem a finalidade de identificar, mas de sinalizar para o processo avaliativo que se dá pela provisão, e tem a observação direta do comportamento como elemento chave. No momento da pesquisa, além do Guia, o encaminhamento para o AEE também ocorria por indicação direta de professores, colegas, autoindicação e outros; porém, os professores especializados não explicitaram como acontecia o acompanhamento e a avaliação dos indicadores de $\mathrm{AH} / \mathrm{SD}$.

A falta de formação docente adequada impõe barreiras para que os alunos com AH/SD tenham suas capacidades estimuladas a partir de práticas educacionais 
http://dx.doi.org/10.5902/1984686X34664

desafiadoras, a fim de que thes seja oferecido o ensino apropriado às suas singularidades e para que possam usufruir o direito de frequentar o AEE. Para que tais medidas sejam concretizadas, carece-se de um processo anterior, o de identificação, e o mesmo também é válido para o aluno precoce.

A precocidade é entendida como um desenvolvimento prematuro apresentado em qualquer área de domínio (CUPERTINO, 2008) e que, depois de concluída a periodização do desenvolvimento infantil, desaparece sem deixar rastros, ou, ao contrário, evidencia a presença de superdotação enquanto fenômeno estável. Logo, o aluno precoce também requer atenção educacional diferenciada, devendo ser identificado e incentivado no desenvolvimento de suas potencialidades.

Saber se a precocidade observada é um sinal da presença de AH/SD ou uma prematuridade de desenvolvimento momentânea é uma tarefa complexa. A criança deve ser acompanhada durante sua infância, verificando-se se a habilidade apresentada é contínua. Ainda que tal habilidade se mostre estável como o passar dos anos, a constatação da presença de AH/SD depende, igualmente, de outros fatores. De acordo com Renzulli (1978), a superdotação deriva da interação entre três traços: criatividade, habilidade acima da média e comprometimento com a tarefa. Assim, não se trata da atribuição instantânea de um diagnóstico, mas de uma avaliação processual que demanda que a criança esteja em interação com sua área de domínio e possa expressar seus conhecimentos, facilidades, potencial criador e envolvimento. Até o momento em que se possa confirmar ou refutar, com relativa segurança, a hipótese de AH/SD, prefere-se aludir a indicadores de $\mathrm{AH} / \mathrm{SD}$, os quais precisam ser identificados e acompanhados.

Ao nos referirmos a uma segurança relativizada, tomamos por base os ensinamentos de Reis e Renzulli (2009), que advertem sobre a possível transitoriedade da expressão das $\mathrm{AH} / \mathrm{SD}$, que se fazem presentes somente em algumas pessoas, em determinados momentos e sob certas circunstâncias. Isto é, pode-se ter a impressão de inexistência das $\mathrm{AH} / \mathrm{SD}$ porque estas, de modo geral, não se apresentam globalmente, mas em áreas/tarefas específicas. Também é possível crer que uma habilidade anteriormente exibida desapareceu, quando na realidade as situações é que não são propícias para sua manifestação e/ou estabilidade. Posto isso, reforçamos a complexidade do processo de identificação e avaliação das AH/SD.

É certo que a identificação deve envolver múltiplos critérios, e, entre os métodos mais comumente empregados, encontram-se os testes padronizados, nomeação de professores, 
http://dx.doi.org/10.5902/1984686X34664

nomeação de pais, nomeação de colegas, autonomeação e avaliações do trabalho escolar desenvolvido pelo aluno, longitudinalmente (ACEREDA; SASTRE, 1998; MENDONÇA; RODRIGUES; CAPELLINI, 2017).

A princípio, compreendia-se a superdotação como QI elevado e, em decorrência disso, avaliava-se sua presença exclusivamente de maneira quantitativa, a partir da aplicação de testes padronizados. Contudo, Guimarães e Ourofino (2007) advertem que os escores de um teste de QI não são capazes de garantir a existência de superdotação, do mesmo modo que não identificam alto potencial para o desenvolvimento de habilidades.

Considerando-se a definição de Renzulli (1978), testes de QI podem sinalizar, somente, a habilidade acima da média na área linguística ou lógico-matemática, de maneira a não fornecer informações sobre a criatividade e o envolvimento com a tarefa, bem como sobre as habilidades em outros campos do fazer humano.

Com o reconhecimento da superdotação enquanto um fenômeno multidimensional, juntamente com as limitações próprias dos testes de inteligência, a identificação passou a ser considerada muito mais complexa, em razão da impossibilidade de se sustentar a identificação na aplicação de um único teste, o qual se destina a quantificar a inteligência (ALENCAR; FLEITH, 2001). Contudo, o uso de tais testes tende a ser bem aceito por vários estudiosos da área, quando associados a métodos qualitativos. Nessa direção, Alcón (2005) considera que a estratégia de identificação mais adequada conjuga procedimentos informais (nomeações/sinalizações) e instrumentos padronizados. Em relação aos procedimentos informais, a autora salienta que os professores são importantes ao fornecerem informações relevantes quanto à capacidade e ao desempenho escolar dos estudantes, na medida em que os pais também podem atentar para capacidades percebidas no ambiente familiar; já os colegas de classe são capazes de oferecer informações valiosas sobre aqueles que se destacam em sala de aula e fora dela.

Segundo os Subsídios para organização e funcionamento de serviços de Educação Especial: área de Altas Habilidades (BRASIL, 1995a), a identificação deve combinar observações, testes individuais ou coletivos e avaliação de desempenhos. É indicado que se inicie pela sinalização daqueles que se sobressaem no grupo, em virtude de elevada potencialidade numa determinada área. Para tanto, é possível utilizar questionários, listas de traços e características relacionados às AH/SD. No que tange à aplicação de testes, os destinados a mensurar a inteligência não costumam ser práticos à escola, visto que envolvem serviços da área de Psicologia, nem sempre disponíveis nos sistemas públicos 
http://dx.doi.org/10.5902/1984686X34664

de ensino, além de os custos da aplicação de tais instrumentos serem elevados. Assim, o uso de testes depende das condições disponíveis, sendo que podem ser elaborados ou adaptados na própria escola a fim de propiciar informações objetivas sobre o desempenho do discente nas esferas física, intelectual, de liderança, criatividade, psicomotora e artística.

Nessa ótica, ressalta-se que, na ausência de profissionais especializados para a identificação desses estudantes, o professor de sala regular assume o papel central nesse processo.

Deve-se considerar também a possibilidade de se levantar esse perfil sem se contar com técnicos, especialistas e equipes de avaliação. Nesse caso, o professor assume mais um grande papel: a avaliação minuciosa, detalhada, completa e real de seu aluno (BRASIL, 1995b, p. 20).

Ainda que haja uma equipe multidisciplinar envolvida no processo identificador, o professor não deixa de ter sua importância, sendo ele quem diariamente observa, avalia e indica os alunos que se destacam perante o coletivo (GUIMARÃES; OUROFINO, 2007). Dessa maneira, observa-se que a relevância do professor no processo de identificação é amplamente reconhecida (POCINHO, 2009; PÉREZ; FREITAS, 2016), pois o conhecimento desse profissional acerca do desenvolvimento infantil e a convivência diária com várias crianças de faixa etária e origem socioeconômica semelhantes lhe permitem perceber comportamentos e habilidades diferenciadas entre os estudantes do grupo. Entretanto, a pesquisa e a prática com a formação de professores para a identificação das $\mathrm{AH} / \mathrm{SD}$ têm nos revelado que, além da necessidade de conhecimentos sobre a temática, os educadores clamam por instrumentos que os auxiliem nessa identificação, uma vez que se sentem inseguros diante da subjetividade da indicação. Foi a atenção a essa demanda que principiou o surgimento da Escala de Identificação de Precocidade e Indicadores de Altas Habilidades/Superdotação (EIPIAHS).

\section{Escala de Identificação de Precocidade e Indicadores de Altas Habilidades/Superdotação}

A construção de um instrumento de avaliação adequado a determinada população e realidade sociocultural não é tarefa simples e demanda revisões e adaptações constantes. A EIPIAHS encontra-se em processo de construção há algum tempo, e a experiência com o instrumento tem apontado caminhos para aprimorá-lo.

No ano de 2012, ao iniciar o curso de Mestrado em Educação, fizemos um levantamento dos principais instrumentos/checklists de identificação de AH/SD disponíveis 
http://dx.doi.org/10.5902/1984686X34664

para professores (DELOU, 1987; GUENTHER, 1997; FREITAS; PÉREZ, 2010) e percebemos que as características abordadas se distinguiam. A partir daí, iniciamos um levantamento das características apontadas na literatura, a fim de ampliar a relação, bem como a possibilidade de identificação por parte dos professores.

Consultamos referenciais nacionais e internacionais, registrando os traços descritos pelos autores de livros, artigos, teses e dissertações sobre pessoas com AH/SD. O levantamento chegou ao fim quando as fontes consultadas começaram a apresentar apenas características já arroladas, que totalizaram 109. O objetivo desta listagem era oferecê-la aos professores como parte integrante de um manual de orientações com 0 intuito de lhes fornecer subsídios para a identificação de estudantes precoces com indicadores de AH/SD (MARTINS, 2013).

Essa lista foi submetida à análise de juízes que classificaram as características em: gerais de altas habilidades/superdotação, de pensamento criativo e de aprendizagem. Durante esse processo, foram eliminadas aquelas consideradas de difícil avaliação por parte do professor, como, por exemplo, possuir alergias não apresentadas por outras pessoas da família. Com isso, o instrumento passou a ter 75 características, que serão especificadas a seguir.

Características gerais: perseverança diante de dificuldades; elaboração de deduções e inferências; envolvimento com o que gosta de fazer durante longo período de tempo; liderança; grande capacidade perceptivo-espacial; senso de justiça, moral e ético bem desenvolvidos; interesses diferenciados em relação aos colegas; ampla gama de informações no que se relaciona à sua área de interesse; motivação para trabalhar nesta área; gosto por trabalhar/estudar sozinho; tendência a chamar a atenção dos demais; perfeccionismo; independência na realização das atividades; facilidade de expressão (oral ou escrita); ansiedade por fazer o que gosta; preferência por jogos de estratégia; cooperação com os colegas; investimento de energia emocional em suas realizações; organização e eficiência em tarefas e problemas de seu interesse; alto nível de energia; curiosidade; questionamento de regras e autoridade; observação; autenticidade; sensibilidade emocional.

Características de pensamento criativo: inconformismo e pensamento independente; originalidade; ideias inesperadas ou extravagantes; senso de humor avançado para a idade; flexibilidade para rever pontos de vista e aceitar opiniões; visualização de consequências; gosto por desafios e enfrentamento de riscos; percepção; imaginação; 
http://dx.doi.org/10.5902/1984686X34664

criatividade; exposição de ideias sem medo de críticas; uso de analogias e combinações incomuns; coragem para discordar e expor opiniões; apreço por novas experiências; preferência por atividades novas e criadoras; capacidade para construir hipóteses; elaboração de histórias vívidas; criação de soluções próprias para resolver problemas.

Características de aprendizagem: capacidade incomum de raciocínio; habilidades em áreas específicas; boa memória; habilidades metacognitivas; boas notas em sua área de interesse; interesse por causas e razões das coisas; gosto por quebra-cabeças e jogosproblema; capacidade de organização e planejamento; rapidez e facilidade de aprendizagem em áreas de interesse; rapidez no estabelecimento de relações e compreensão de significados; pensamento ágil; progresso rápido; capacidade de análise, avaliação e julgamento; capacidade para generalizar; relacionamento entre conhecimentos novos e anteriormente adquiridos; satisfação em pensar e discutir o que leu; estabelecimento de relações entre causa e efeito; prazer pela atividade intelectual; identificação de inconsistências; amplo vocabulário; tendência a que lhe peçam ideias e sugestões; preferência por abstrações; precocidade, gosto e nível elevado de leitura; capacidade para pronta resposta; gosto pelo ambiente escolar; exploração de temas em profundidade; manutenção da concentração e atenção por longos períodos em atividades de interesse; atitude de questionamento e busca por informações; amplitude de foco; capacidade para relatar com riqueza de detalhes; pensamento crítico; distração, tédio e desmotivação em tarefas que não são de seu interesse.

Durante o processo de elaboração do manual, seguindo-se as recomendações de Echer (2005), a última etapa consistiu em sua qualificação a partir da avaliação de professores da rede pública de Ensino Fundamental. Nessa ocasião, a lista foi considerada pouco funcional, uma vez que não havia a indicação de um ponto de corte que sinalizasse algum possível distanciamento da média.

A ausência de critérios objetivos e validados para a análise dos resultados também era característica dos instrumentos disponíveis até então. A Lista Base de Indicadores de Superdotação - parâmetros para observação de alunos em sala de aula (DELOU, 1987), apresentando 24 características comportamentais (localizadas e selecionadas após um vasto levantamento bibliográfico), poderia ser aplicada em grupo e individualmente, e a avaliação era qualitativa, de maneira que o professor deveria se atentar para a frequência e a consistência dos traços observados. 
http://dx.doi.org/10.5902/1984686X34664

O Questionário para Identificação de Indicadores de Altas Habilidades/superdotação - Professores (FREITAS; PÉREZ, 2010) era um instrumento para avaliação individual que possuía 54 características divididas em: gerais, liderança, habilidade acima da média, criatividade e comprometimento com a tarefa. Porém, destinava-se a estudantes do $5^{\circ}$ ano do Ensino Fundamental ao $3^{\circ}$ ano do Ensino Médio, isto é, não abrangia as crianças precoces.

Cabe destacar que, em 2016, Pérez e Freitas republicaram o referido questionário, agora com 60 características, o qual já não apresenta a indicação de uso para alunos a partir do $5^{\circ}$ ano do Ensino Fundamental, havendo, inclusive, uma versão para Educação Infantil.

Esse instrumento foi, inicialmente, adaptado por Pérez (2004) a partir do questionário usado no Estudo de Prevalência sobre Alunos com Altas Habilidades/Superdotação, desenvolvido na Região Metropolitana de Porto Alegre, pela Associação Brasileira para Superdotados em 2001. Em sua primeira versão, o questionário apresentava 29 questões e foi submetido a um estudo piloto com dez estudantes, cinco deles com AH/SD, e cinco escolhidos aleatoriamente. A versão mais recente (PÉREZ; FREITAS, 2016) também foi submetida a um teste-piloto junto a 38 estudantes com AH/SD, cujas idades variavam de 7 anos e 11 meses a 18 anos. Trata-se de uma tradução e adaptação de um instrumento de Renzulli e Reis, com vasta aceitação e importância no Brasil; entretanto, devido ao baixo número de participantes nos estudos- piloto realizados, bem como à falta de associação com outros instrumentos, não é possível atestar sua validade no contexto nacional. Além disso, o questionário não apresenta um crivo de correção, e a interpretação do resultado deve considerar a frequência e a intensidade dos indicadores evidenciados ao longo do tempo.

Já o Guia de Observação Direta (GUENTHER, 2006) foi elaborado para organizar os dados da observação sistemática de professores em sala de aula, na identificação de estudantes cujas capacidades os destacam, com vista à inscrição no Centro para Desenvolvimento do Potencial e Talento (CEDET), iniciado em 1992. A versão do Guia a que, inicialmente, tivemos acesso continha 25 itens, nos quais o professor deveria indicar dois alunos em cada um deles. Em sua versão mais atual (GUENTHER, 2013), há 31 itens referentes a cinco domínios: Inteligência Geral, Inteligência com profundidade e pensamento não linear, Inteligência com capacidade verbal, Criatividade e potencial 
http://dx.doi.org/10.5902/1984686X34664

criador, Capacidade socioafetiva. A análise dos dados considera o número de indicadores nos diferentes domínios.

A autora afirma que o instrumento passou por um processo de validação no ano de 1995. Em 2001, o processo de identificação passou a integrar a observação assistida por especialistas, a fim de atenuar a margem de erro da observação em sala de aula. Entre 2011 e 2012, o Guia passou por revalidação junto às escolas públicas da cidade de LavrasMG e escolas particulares conveniadas à Associação de Pais e Amigos para Apoio ao Talento (ASPAT). No entanto, não são apresentadas maiores informações sobre os procedimentos e os resultados obtidos nos processos de validação e revalidação. Além disso, o instrumento não foi idealizado para a identificação de crianças na faixa de precocidade, pois a autora compreende que crianças com menos de 10 anos de idade, de modo geral, não necessitam de intervenção educacional complementar à oferecida pela escola, sendo possível acelerar a escolarização daquelas cujo aprendizado ocorra com muita antecedência em relação ao que é próprio para a faixa etária (GUENTHER, 2013).

Isso posto, compreendemos a angústia das professoras que avaliaram o manual diante da subjetividade da identificação proposta e julgamos apropriado estabelecer um ponto de quantificação de características de AH/SD que apontasse para um distanciamento da média.

Sendo assim, convidamos os educadores de uma escola da rede pública a preencher a lista de características de $\mathrm{AH} / \mathrm{SD}$ para dois de seus alunos, um menino e uma menina. $\mathrm{O}$ convite de preenchimento da lista estendeu-se aos professores dos alunos que frequentavam o Programa de Atenção ao aluno Precoce com Comportamento de Superdotação (PAPCS), desenvolvido na Faculdade de Filosofia e Ciências da Universidade Estadual Paulista "Júlio de Mesquita Filho" (Unesp), Campus de Marília ${ }^{1}$. A inclusão das crianças integrantes do PAPCS foi importante por se tratar de um público previamente submetido a um amplo processo de avaliação pedagógica e psicológica, que permitiu a identificação da precocidade e dos indicadores de AH/SD.

No conjunto das escolas da rede pública, a escola eleita foi escolhida em razão do agrupamento peculiar dos alunos, uma vez que tenta estabelecer certa homogeneidade no desempenho dos discentes, separando-os com base no rendimento escolar. Esse tipo de agrupamento, embora pedagogicamente questionável, possibilitou a obtenção de uma amostra composta por alunos de bom, médio e baixo desempenho acadêmico, de modo que 3 professores de cada um dos cinco primeiros anos do Ensino Fundamental I, 
http://dx.doi.org/10.5902/1984686X34664

totalizando 15, deveriam observar a presença das características de AH/SD, constantes na lista a ser assinalada, conforme o que verificavam. Assim, cada professor preencheu o instrumento para dois de seus alunos, um menino e uma menina, cujos critérios de seleção, baseados na percepção das professoras, foram os seguintes: nas turmas em que estavam matriculados os alunos considerados como os melhores, selecionaram-se aqueles de maior desempenho; nas turmas destinadas a alunos regulares, os de desempenho mediano; e, nas turmas restantes, os de baixo desempenho, sempre em relação ao grupo de pertencimento. As 30 listas de características provenientes desse universo foram comparadas às listas preenchidas pelos professores dos alunos que frequentavam 0 PAPCS.

A análise das listas de características preenchidas pelos professores da escola pública revelou a média de 35 características por aluno, de modo que a maioria das crianças apresentava de 31 a 40 características, como mostra a Tabela 1.

Tabela 1 - Distribuição dos alunos segundo o número de características de AH/SD apresentadas $(n=30)$, Marília, 2013

\begin{tabular}{cc}
\hline Características apresentadas & Número de alunos \\
\hline $1-10$ & 4 \\
$11-20$ & 5 \\
$21-30$ & 3 \\
$31-40$ & 8 \\
$41-50$ & 3 \\
$51-60$ & 2 \\
$61-70$ & 5 \\
Acima de 70 & 0 \\
\hline TOTAL & 30
\end{tabular}

Fonte: Elaboração própria (2013).

Quanto às características apresentadas pelos alunos integrantes do PAPCS, obtivemos uma média de 54 delas, estando a maioria localizada no intervalo de 51 a 60 características, como se observa na Tabela 2. 
http://dx.doi.org/10.5902/1984686X34664

Tabela 2 - Distribuição dos alunos do PAPCS segundo o número de características de AH/SD apresentadas $(n=11)$, Marília, 2013

\begin{tabular}{cc}
\hline Características apresentadas & Número de alunos \\
\hline $1-10$ & 0 \\
$11-20$ & 0 \\
$21-30$ & 1 \\
$31-40$ & 0 \\
$41-50$ & 3 \\
$51-60$ & 4 \\
$61-70$ & 2 \\
Acima de 70 & 1 \\
\hline TOTAL & 11 \\
\hline
\end{tabular}

Fonte: Elaboração própria (2013).

A partir dessa comparação, compreendemos que os alunos de escola pública regular que somassem 45 características ou mais estariam sinalizando a presença de indicadores de AH/SD e deveriam ser encaminhados aos serviços de educação especial, para a realização de avaliação pedagógica especializada e possível intervenção.

Desde então, a lista passou a ser usada em pesquisas e programas de extensão universitária (CHACON; MARTINS, 2018; MARTINS, 2016; 2018), quando se percebeu uma variação no número de características em relação à idade e ano escolar dos estudantes, o que inviabiliza o estabelecimento de um ponto de corte arbitrário. Até o momento, o instrumento apresentava o formato de checklist, visto que os professores assinalavam somente as caraterísticas que eram observadas no aluno. A experiência revelou que tal formato não era o mais adequado, pois os professores sentiam necessidade de diferenciar as características que eram percebidas esporadicamente das que apresentavam maior constância. Sendo assim, compreendemos a importância de alterar seu formato para uma escala do tipo likert com três opções de resposta: frequentemente, às vezes, nunca.

\section{Levantamento de instrumentos de identificação atuais}

A fim de conhecer o avanço na construção de instrumentos nacionais destinados à identificação das $\mathrm{AH} / \mathrm{SD}$, realizamos um levantamento de produções científicas publicadas entre 2009 e 2019. As bases de dados consultadas foram o Banco de Teses e Dissertações 
http://dx.doi.org/10.5902/1984686X34664

da Coordenação de Aperfeiçoamento Pessoal de Nível Superior (CAPES), a Biblioteca Digital Brasileira de Teses e Dissertações (BDTD) e os Periódicos CAPES, a partir dos descritores: altas habilidades, superdotação, talento, dotação e precocidade. Os critérios de inclusão compreendiam a adequação semântica dos termos recuperados no que tange ao significado dos descritores enquanto uma necessidade educacional que caracteriza uma parcela do público da Educação Especial: ter a construção de instrumentos como objeto de pesquisa.

A consulta às referidas bases possibilitou-nos localizar três produções, sendo duas dissertações (RIBEIRO, 2013; BASSINELLO, 2014) e quatro artigos publicados em periódicos (NAKANO et al., 2015; NAKANO et al., 2016; NAKANO; CAMPOS; SANTOS, 2016; ZAIA; NAKANO; PEIXOTO, 2018).

Ribeiro (2013) buscou evidências de validade de uma bateria de avaliação psicométrica das AH/SD voltada para a identificação de crianças e adolescentes, a partir de testes de raciocínio (verbal, abstrato, numérico e lógico) e criatividade (figural e verbal), desenvolvida por Nakano e Primi (2012) e ainda não publicada, por estar em fase de análise das propriedades psicométricas por parte seus autores (NAKANO et al., 2015).

Bassinello (2014) teve por objetivo construir uma escala de autorrelato para identificação de características de AH/SD a partir de 44 itens respondidos por estudantes na faixa etária de 9 a 12 anos. Esses itens estão associados a 22 características de AH/SD apontadas na literatura, e a análise fatorial exploratória (AFE) apontou para quatro fatores. A versão inicial da escala foi reavaliada por AFE (ZAIA; NAKANO; PEIXOTO, 2018), resultando na exclusão de seis itens e solução de dois fatores, denominados Características Socioemocionais e Características Cognitivas.

Nakano et al. (2015) realizaram análise dos itens da Bateria para Avaliação das Altas Habilidades/Superdotação (BAAH/S), que revelou a adequação da maioria desses itens, havendo alguns com necessidades de revisão.

Nakano, Campos e Santos (2016) verificaram a validade de conteúdo, a partir da concordância entre juízes, da Escala de Avaliação de Altas Habilidades - Versão Professor, e Nakano et al. (2016) investigaram a relação dessa escala com o desempenho estudantil na BAAH/S. A referida escala compõe o conjunto de instrumentos psicológicos que integram a BAAH/S e é respondida por professores no que diz respeito às competências escolares, habilidades específicas, áreas de avaliação, atitudes para a aprendizagem e 
http://dx.doi.org/10.5902/1984686X34664

áreas de desenvolvimento, sendo uma versão baseada na Gifted Rating Scale (PFEIFFER; JAROSEWICH, 2003).

\begin{abstract}
A escala, desenvolvida especificamente para fazer parte da bateria, deve ser respondida pelo professor para avaliar o estudante, cuja informação é utilizada como segunda forma de coleta de dados e busca de informação sobre a avaliação individual, com o objetivo de proporcionar dados sobre o desenvolvimento em áreas específicas (NAKANO et al., 2016, p. 86, tradução nossa).
\end{abstract}

Os instrumentos mencionados são de fundamental importância para a identificação das AH/SD e se configuram como recursos de avaliação psicológica. Os autores enfatizam a necessidade de ampla investigação sobre suas qualidades psicométricas com vistas à aprovação no Sistema de Avaliação dos Testes Psicológicos, do Conselho Federal de Psicologia e disponibilização para uso profissional.

Sabe-se que a identificação e avaliação das AH/SD é um processo multidimensional que envolve diferentes sujeitos e se beneficia com o suporte de instrumentos psicológicos, em especial, quando elaborados especificamente para esse fim. Contudo, é nítida a dificuldade de acesso a esses materiais, bem como aos serviços de Psicologia por parte dos sistemas públicos de ensino, ao mesmo tempo que existe a carência de instrumentos Pedagógicos nacionais rigorosamente construídos e validados.

A despeito da competência e dos conhecimentos do professor acerca de seus alunos, há a tendência de desqualificar sua indicação, compreendida como demasiadamente subjetiva, o que evidencia a importância de instrumentos pedagógicos que orientem o processo de identificação.

Considerando-se a relevância dos professores na identificação da precocidade e de indicadores de $\mathrm{AH} / \mathrm{SD}$, esta investigação tem por objetivo avaliar os itens e verificar a consistência de um instrumento para identificação de alunos com indicadores de altas habilidades/superdotação no Ensino Fundamental I.

\title{
Método
}

O estudo foi realizado em escolas públicas localizadas no interior do estado de Mato Grosso do Sul (MS), tendo, como participantes, professores graduados em Pedagogia e atuantes no $1^{\circ}$ ao $5^{\circ}$ ano do Ensino Fundamental I. 
http://dx.doi.org/10.5902/1984686X34664

\section{Procedimentos éticos}

Após a aprovação do projeto de pesquisa por parte do Comitê de Ética em Pesquisa da Universidade Federal de Mato Grosso do Sul (parecer no 3.831.276), convidamos os professores a participar, cujo aceite foi expresso mediante assinatura do Termo de Consentimento Livre e Esclarecido, depois de explicitados os propósitos do estudo e sanadas todas as dúvidas.

\section{Procedimentos para coleta de dados}

Entramos em contato com os coordenadores das escolas municipais de uma cidade do interior de MS, a fim de que encaminhassem o convite de participação na pesquisa a todos os professores. Obtivemos retorno de 18 professoras, as quais concordaram em avaliar uma lista com as 75 características de AH/SD integrantes da EIPIAHS, indicando aquelas que julgavam passíveis de serem observadas no contexto de sala de aula.

A EIPIAHS foi aplicada por 10 professores em 71 estudantes de $1^{\circ}$ ao $5^{\circ}$ ano do Ensino Fundamental de uma escola pública, previamente selecionados por meio do Questionário de Autonomeação e Nomeação por Colegas (PÉREZ; FREITAS, 2016) ou por indicação de professores em razão de considerarem que tais estudantes se destacam significativamente dos demais.

Os professores tinham diante de si três opções de resposta para cada item: "nunca", "às vezes" e "frequentemente". Os itens em que foi assinalada a opção "nunca" receberam pontuação nula; "às vezes", um ponto; e "frequentemente", dois pontos.

\section{Procedimentos para análise de dados}

Os dados foram analisados quantitativamente, com o uso de planilhas do Excel (Microsoft Office 2013) e do pacote IBM Statistical Package for Social Sciences (SPSS), em sua versão 24.0. Analisamos a somatória da pontuação obtida em cada item durante a aplicação da EIPIAHS, destacando aqueles que apresentaram até 47 pontos, o equivalente a um terço da pontuação máxima que seria possível obter. Esses resultados foram confrontados com a análise que as 18 professoras fizeram acerca da lista de caraterísticas passíveis de serem observadas em sala de aula, a fim de excluir os itens com baixa funcionalidade. Dessa maneira, os itens pouco assinalados durante a aplicação da escala que também apareciam como difíceis de serem observados em sala de aula, segundo a percepção dos professores, foram discutidos e analisados qualitativamente no Grupo de 
http://dx.doi.org/10.5902/1984686X34664

Estudos e Pesquisas em Educação Inclusiva (GEPEI), da Universidade Federal de Mato Grosso do Sul, com vistas a decidir, coletivamente, sobre a exclusão ou reformulação de cada item. Feitas as adequações na escala, sua consistência interna foi analisada por meio do coeficiente de Alfa de Cronbach.

\section{Resultados e discussão}

As 75 características presentes na EIPIAHS foram analisadas por 18 professores que consideraram a faixa etária dos alunos e o ano escolar no qual atuavam. Consideramos a avaliação desses professores dividindo-os em dois grupos: $1^{\circ}$ e $2^{\circ}$ ano (6 professores); $3^{\circ}$, $4^{\circ}$ e $5^{\circ}$ ano (12 professores). Essa divisão foi necessária porque o uso do instrumento tem revelado que os alunos dos dois primeiros anos do Ensino Fundamental apresentam um número menor de características que os de anos subsequentes. Nessa direção, os professores de $1^{\circ}$ e $2^{\circ}$ ano expressaram dificuldade em observar 18 características que os demais professores conseguiam visualizar em seus alunos. São elas: organização e eficiência no que se refere a tarefas e resolução de problemas de seu interesse; alto nível de energia e atividade; questionamento e desafio de regras e autoridade; inconformismo e pensamento independente; ideias inesperadas ou originais e extravagantes; uso de analogias e combinações incomuns; coragem para discordar, expor ideias e opiniões; apreço por novas experiências; habilidades metacognitivas e autorreguladoras da aprendizagem; boas notas em áreas de interesse; agilidade de pensamento; progresso rápido; identificação de inconsistências; capacidade para pronta resposta; exploração de temas em profundidade; amplitude de foco; relatos ricos em detalhes; outros alunos lhe pedem ideias e sugestões.

Algumas dessas características, como inconformismo e questionamento de regras, tendem a ser menos comuns em crianças menores, o que não significa que não possam ser apresentadas, sobretudo, por crianças precoces. Já outras, como exploração de temas em profundidade, fazer relatos ricos em detalhes, dar ideias e sugestões aos colegas, dependem das oportunidades oferecidas pelo ambiente, de modo a estarem relacionadas com as metodologias de ensino adotadas. No que se refere a ter boas notas em áreas de interesse, essa característica mostrou-se inadequada às turmas de primeiro ano do contexto investigado, pois não há atribuição de notas nessa etapa, mas o acompanhamento de desempenho, o que justifica a alteração da redação, substituindo-se notas por desempenho. 
http://dx.doi.org/10.5902/1984686X34664

Gomes (2010) encontrou relação entre a inteligência fluida e as notas escolares, de maneira que as estruturas formais de pensamento e a capacidade de raciocínio abstrato exercem influência nas notas tanto em contextos mais construtivistas quanto nos tradicionais. Contudo, as notas nada mais são do que medidas de desempenho, o qual pode ser avaliado de diversas maneiras.

Já o grupo de professores de $3^{\circ}$ ao $5^{\circ}$ ano destoou dos demais ao compreender como difíceis de serem observadas as seguintes características: senso de humor avançado para a idade; flexibilidade para rever pontos de vista e aceitar outras opiniões. É possível que essa diferença esteja relacionada a uma maior liberdade para dialogar, expressar opiniões e fazer brincadeiras nos primeiros anos, em contraponto à cobrança por silêncio e "disciplina", compreendidos como sinônimo de bom comportamento. Segundo Lapa (2017), embora a importância da ludicidade seja tema recorrente na formação inicial e continuada de professores, as práticas de ensino tendem a se aproximar de um modelo mais tradicional, o que se intensifica à proporção que os anos escolares avançam, tendo como alegação a falta de tempo, de material, de formação, de motivação com a carreira e de crédito no potencial impulsionador de aprendizagem que a ludicidade carrega.

Ao analisarmos os resultados da EIPIAHS junto aos 71 alunos avaliados, 26 itens apresentaram baixa pontuação, obtida a partir da somatória referente a todos os alunos. $\mathrm{Na}$ sequência, confrontamos tais itens com as características que apenas foram assinaladas como passíveis de serem observadas por até um terço dos professores em ao menos um dos grupos. A partir desse cotejo, identificamos 16 itens com baixa pontuação obtida durante a aplicação na escola, os quais também foram pouco sinalizados como passíveis de observação no momento em que os professores avaliaram o instrumento. Tais itens foram submetidos a análise de um grupo de pesquisadores em educação inclusiva que estuda a temática das AH/SD, a fim de decidir, coletivamente, sobre a manutenção, exclusão ou modificação de cada um deles. Verificamos também o coeficiente de Alfa de Cronbach se o item for excluído. O Quadro 1 apresenta essas características e a decisão tomada a respeito de cada uma delas. 
Quadro 1 - Decisão sobre as características pouco assinaladas durante a aplicação da EIPIAHS

\begin{tabular}{|c|c|c|c|}
\hline Item & Característica & \begin{tabular}{|c|} 
Alfa de \\
Cronbach se \\
tem excluído
\end{tabular} & Decisão \\
\hline 20 & $\begin{array}{l}\text { Apresenta alto nível de } \\
\text { energia. É muito ativo. }\end{array}$ & 0,963 & $\begin{array}{l}\text { Característica que faz com que muitos alunos } \\
\text { sejam equivocadamente diagnosticados com } \\
\text { Transtorno do Déficit de Atenção e Hiperatividade } \\
\text { (TDAH). Mantido. }\end{array}$ \\
\hline 22 & $\begin{array}{l}\text { Questiona ou desafia regras e } \\
\text { autoridade. }\end{array}$ & 0,964 & $\begin{array}{l}\text { Importante para identificar alunos que se } \\
\text { distanciam do estereótipo de bom aluno. Mantido. }\end{array}$ \\
\hline 26 & $\begin{array}{l}\mid \hat{E} \text { inconformista e pensa de } \\
\text { maneira independente. }\end{array}$ & 0,963 & Excluído. \\
\hline 28 & $\begin{array}{l}\text { Apresenta ideias inesperadas } \\
\text { ou originais e extravagantes. }\end{array}$ & 0,963 & $\begin{array}{l}\text { Optou-se pela exclusão do termo "extravagantes" } \\
\text { que pode provocar interpretações equivocadas. }\end{array}$ \\
\hline 29 & $\begin{array}{l}\text { Demonstra senso de humor } \\
\text { avançado para sua idade. }\end{array}$ & 0,964 & $\begin{array}{l}\text { Indicador de criatividade que não condiz com a } \\
\text { imagem estereotipada de estudante com AH/SD. } \\
\text { Mantido. }\end{array}$ \\
\hline 32 & $\begin{array}{l}\text { Gosta de enfrentar desafios e } \\
\text { correr riscos. }\end{array}$ & 0,963 & Excluído. \\
\hline 37 & $\begin{array}{l}\text { Faz uso de analogias e } \\
\text { combinações incomuns. }\end{array}$ & 0,964 & Excluído. \\
\hline 47 & $\begin{array}{|lr|}\text { Apresenta } & \text { habilidades } \\
\text { metacognitivas } & \text { (pensa sobre } \\
\text { seu próprio pensamento) } & \text { e } \\
\text { autorreguladoras } & \text { da } \\
\text { aprendizagem. } & \end{array}$ & 0,963 & Excluído. \\
\hline 56 & \begin{tabular}{|lr} 
Demonstra & capacidade \\
desenvolvida de análise, \\
avaliação e julgamento.
\end{tabular} & 0,962 & Excluído. \\
\hline 57 & $\begin{array}{l}\text { Tem capacidade para fazer } \\
\text { generalizações. }\end{array}$ & 0,963 & Excluído. \\
\hline 62 & $\begin{array}{l}\text { Identifica inconsistências } \\
\text { rapidamente. }\end{array}$ & 0,963 & Excluído. \\
\hline 65 & Prefere lidar com abstrações. & 0,964 & Excluído. \\
\hline 66 & $\begin{array}{l}\text { Demonstra precocidade, gosto } \\
\text { e nível elevado de leitura. }\end{array}$ & 0,963 & $\begin{array}{l}\text { A precocidade na leitura só pode ser observada em } \\
\text { crianças que estão em etapas antecedentes ou } \\
\text { iniciais de alfabetização, por isso, optou-se por } \\
\text { alterar a redação: Gosta de ler e apresenta nível } \\
\text { elevado de leitura. }\end{array}$ \\
\hline 67 & $\begin{array}{l}\text { Tem capacidade para pronta } \\
\text { resposta. }\end{array}$ & 0,963 & Excluído. \\
\hline 69 & $\begin{array}{|lr|}\begin{array}{l}\text { Explora temas } \\
\text { profundidade. }\end{array} & \text { em } \\
\end{array}$ & 0,963 & Excluído. \\
\hline 72 & $\begin{array}{l}\text { Demonstra amplitude de foco } \\
\text { (parece distraído, mas está } \\
\text { atento a mais de uma coisa). }\end{array}$ & 0,963 & $\begin{array}{l}\text { Importante para identificar alunos que podem } \\
\text { parecer desatentos. Mantido. }\end{array}$ \\
\hline
\end{tabular}

Fonte: Elaboração própria (2020).

Os pesquisadores discutiram, em reunião do grupo de pesquisa, cada um dos itens individualmente, levando-se em conta os seguintes critérios para tomada de decisão: excluir aqueles que não são suficientemente claros e compreensíveis; excluir aqueles que sofrem grande influência do contexto educacional, dependendo das metodologias educacionais adotadas para que possam se manifestar; modificar os que podem ser clarificados ou se 
http://dx.doi.org/10.5902/1984686X34664

tornarem mais específicos a partir de pequenos ajustes; manter os que são necessários à identificação de estudantes que se afastam da imagem de "aluno ideal".

Souza, Alexandre e Guirardello (2017) salientam a importância de especialistas na avaliação do conteúdo de um instrumento, em razão de não existirem testes estatísticos com essa finalidade, o que faz com que esse tipo de análise qualitativa seja o método mais recorrente para garantir a validade de conteúdo.

Excluídos os itens 26, 32, 37, 47, 56, 57, 62, 65, 67 e 69 e mantendo-se a redação dos itens 28 e 66, analisamos a consistência interna da escala por meio do coeficiente de Alfa de Cronbach, cujos resultados foram 0,89;0,85;0,90;0,96, respectivamente, nas características gerais de AH/SD (25 itens), características de pensamento criativo (15 itens), características de aprendizagem (25 itens) e escala completa (65 itens), o que indica que a escala apresenta confiabilidade. Novas análises serão realizadas futuramente, com amostras maiores, a fim de aprimorar o instrumento e suas qualidades psicométricas, bem como para validá-lo.

Cabe ressaltar que, mesmo após concluído o processo de validação, a EIPIAHS, por si só, não será suficiente para atestar a presença de $A H / S D$, uma vez que isso requer uma avaliação continua e longitudinal, que pode demandar distintos meios, conforme as habilidades manifestadas.

A relevância de instrumentos voltados especificamente para a área das $A H / S D$ é apontada por Nakano, Campos e Santos (2016), uma vez que há a tendência de restringir a identificação e avaliação das capacidades elevadas a testes objetivos destinados à população geral, em especial, os que se propõem a mensurar a inteligência e a criatividade. Tal predomínio pode ser entendido como decorrência do prestígio dos testes psicológicos, ainda que a inteligência seja um conceito complexo - cuja definição não é consensual -, compreendido a partir de diferentes modelos e perspectivas teóricas que subjazem os testes, e ainda que a criatividade seja um constructo cuja avaliação objetiva é contestável, uma vez que se evidencia em produtos que fogem à norma (ALMEIDA, 1994; SÁNCHEZ ANEAS, 2013; MORAIS; FLEITH, 2017).

Tais constatações tornam evidente a secundarização dos educadores das mais diversas áreas no processo identificador, a despeito do saber científico disciplinar que eles possuem, associado ao conhecimento sobre o processo de desenvolvimento estudantil típico, fatores de grande importância para o reconhecimento de discentes com habilidades sobressalientes em determinadas áreas de domínio. 
http://dx.doi.org/10.5902/1984686X34664

Nesse prisma, ressalta-se a necessidade de instrumentalização dos docentes a fim de que possam identificar e avaliar, pedagogicamente, habilidades superiores em seus estudantes, inclusive na fase de precocidade, fenômeno ainda pouco investigado nacionalmente (MARQUES; COSTA; RANGNI, 2015). Assim, a EIPIAHS é uma ferramenta que reconhece a importância do professor no processo de identificação (PÉREZ; FREITAS, 2016) e o auxilia no reconhecimento de alunos precoces com indicadores de AH/SD, os quais devem ser encaminhados aos serviços de Educação Especial para a continuidade do processo avaliativo e intervenções cabíveis.

\section{Considerações finais}

Com o objetivo de avaliar seus itens e verificar a consistência da EIPIAHS, contamos com a participação de 18 professores do Ensino Fundamental I que avaliaram o instrumento e outros 10 que o aplicaram a uma amostra de 71 alunos indicados por eles ou por colegas de classe como estudantes de destaque. Na sequência, os itens foram analisados quantitativamente, e aqueles de baixa incidência foram analisados qualitativamente, o que resultou na exclusão, alteração ou manutenção de cada um deles. A análise da confiabilidade da escala e de seus subcomponentes revelou que o instrumento possui elevada consistência interna, de modo a apresentar fidedignidade.

Em continuidade ao processo de validação da escala, o instrumento será aplicado a uma ampla amostra e submetido à análise fatorial exploratória, a qual poderá resultar na eliminação de outros itens, bem como na configuração de subcategorias que difiram da divisão entre características gerais, de aprendizagem e de pensamento criativo, pois identificadas a partir de fatores latentes.

Como implicações para futuras pesquisas, sugere-se a replicação do estudo em outros contextos geográficos com o intuito de comparar os resultados obtidos. A aplicação do instrumento em outros níveis de ensino pode desencadear adaptações e a validação da escala para uso em outras etapas educacionais. Recomendam-se, ainda, novos investimentos científicos na produção de instrumentos pedagógicos que auxiliem o professor no processo de identificação da precocidade e das altas habilidades/superdotação. Por fim, salienta-se que o professor é peça fundamental no processo de identificação de potencialidades em sala de aula e necessita ser suficientemente instruído e instrumentalizado para essa relevante tarefa. 
http://dx.doi.org/10.5902/1984686X34664

\section{Referências}

ACEREDA, Amaro; SASTRE, Silvia. La superdotación. Madrid: Síntesis Psicología, 1998.

ALCÓN, María del Carmen Granado. El niño superdotado: fundamentos teóricos y psicoeducativos. Badajoz: @becedario, 2005.

ALENCAR, Eunice Maria Lima Soriano; FLEITH, Denise de Souza. Superdotados: determinantes educação e ajustamento. 2. ed. São Paulo: EPU, 2001.

ALMEIDA, Leandro da Silva. Inteligência: definição e medida. Aveiro: CIDInE, 1994.

BALBIM, Guilherme Moraes; VIEIRA, Lenamar Fiorese. Validação para a população brasileira da Escala de Dominância Télica (TDS) no contexto esportivo. Revista Brasileira de Educação Física e Esporte, São Paulo, v. 29, n. 04, p. 641-651, out./dez. 2015.

BASSINELLO, Priscila Zaia. Construção de escala de autorrelato para identificação de características associadas à superdotação. Campinas: PUC, 2014. Dissertação (Mestrado em Psicologia) - Programa de Pós-Graduação, Centro de Ciências da Vida, Pontifícia Universidade Católica de Campinas, Campinas, 2014.

BARRETO, Célia Maria Paz Ferreira; METTRAU, Marsyl Bulkool. Altas habilidades: uma questão escolar. Revista Brasileira de Educação Especial, Marília, v. 17, n. 03, p. 413426, set./dez. 2011.

BRASIL. Subsídios para organização e funcionamento de serviços de educação especial: área de Altas Habilidades. Brasília, DF: MEC/SEESP, 1995a.

BRASIL. Diretrizes gerais para o atendimento educacional aos alunos portadores de altas habilidades/superdotação e talentos. Brasília, DF: MEC/SEESP, 1995b.

CHACON, Miguel Claudio Moriel; MARTINS, Bárbara Amaral. Programa de Atenção a alunos Precoces com Comportamento de Superdotação: identificação, avaliação e enriquecimento extracurricular e familiar. Sobredotação, Braga, v. 15, n. 2, p. 49-72, 2018.

CUPERTINO, Christina Menna Barreto. (Org.). Um olhar para as altas habilidades: construindo caminhos/Secretaria da Educação. São Paulo: FDE, 2008.

CRUZ, Carly. Serão as altas habilidades/superdotação invisíveis?. 2014. 167f. Tese (Doutorado em Educação), Centro de Educação, Universidade Federal do Espírito Santo, Vitória, 2014. 
DELOU, Cristina Maria Carvalho. Identificação de superdotado: uma alternativa para sistematização da observação de professores em sala de aula. Rio de Janeiro: UERJ, 1987. 181 f. Dissertação (Mestrado em Educação) - Programa de Pós-Graduação, Centro de Educação e Humanidades, Universidade Estadual do Rio de Janeiro, Rio de Janeiro, 1987.

ECHER, Isabel Cristina. Elaboração de manuais de orientação para o cuidado em saúde. Revista Latino-Americana de Enfermagem, Ribeirão Preto, v. 13, n. 5, p. 754-757, set./out., 2005.

FREITAS, Soraia Napoleão; PÉREZ, Susana Graciela Pérez Barrera. Altas habilidades/superdotação: atendimento especializado. Marília, SP: ABPEE, 2010.

GOMES, Cristiano Mauro Assis. Avaliando a avaliação escolar: notas escolares e inteligência fluida. Psicologia em Estudo, Maringá, v. 15, n. 4, p. 841-849, out./dez. 2010.

GUENTHER, Zenita Cunha. Anais... In II Encontro Nacional Sobre Educação de Bem Dotados. Lavras: UFLa, 1997.

GUENTHER, Zenita Cunha. Desenvolver Capacidades e Talentos: um conceito de inclusão. 2. ed. revisada. Vozes, 2006.

GUENTHER, Zenita Cunha. Identificação de Alunos Dotados e Talentosos: Metodologia do CEDET versão 2012. CEDET - ASPAT, Lavras, MG. 2013.

GUIMARÃES, Tânia Gonzaga; OUROFINO, Vanessa Terezinha Alves Tentes. Estratégias de identificação do aluno com altas habilidades/superdotação. In: FLEITH, Denise Souza (Org.). A construção de práticas educacionais para alunos com altas habilidades/superdotação. Brasília: Ministério da Educação, Secretaria de Educação Especial, 2007.

LAPA, Luis Dionísio Paz. A ludicidade como ferramenta no processo de ensinoaprendizagem da Matemática. Passeando por Brasília e aprendendo geometria. Experiências numa escola da periferia do Distrito Federal. 2017. Dissertação (Mestrado Profissional em Matemática) - Instituto de Ciências Exatas, Universidade de Brasília, Brasília, 2017.

MARÔCO, João. Análise de equações estruturais: fundamentos teóricos, software e aplicações. Pêro Pinheiro: Report Number; 2010.

MARQUES, Danitiele Maria Calazans; COSTA, Maria Piedade Resende da; RANGNI, Rosemeire de Araújo. Análise das produções científicas sobre precocidade de crianças com elevado potencial na educação infantil. Horizontes - Revista de Educação, Dourados, MS, v.3, n.5, jan./jun. 2015. 
MARTINS, Bárbara Amaral. Alunos precoces com indicadores de altas habilidades/superdotação no ensino fundamental I: identificação e situações (des)favorecedoras em sala de aula. 2013. Dissertação (Mestrado em Educação) Faculdade de Filosofia e Ciências, Universidade Estadual Paulista, Marília, 2013.

MARTINS, Bárbara Amaral. Identificando alunos com indicadores de altas habilidades/superdotação: um projeto de extensão. In: Congresso Brasileiro de Educação Especial, 7, 2016. São Carlos. Anais... São Carlos: Universidade Federal de São Carlos, 2016, p. 1-16.

MARTINS, Bárbara Amaral. Autoeficácia docente no contexto da educação inclusiva: instrumentos de medida e formação de professores baseada em experiências vicárias. Tese (Doutorado em Educação), Universidade Estadual Paulista, Marília, Brasil, 2018.

MARTINS, Bárbara Amaral; CHACON, Miguel Claudio Moriel. Checklist de identificação de precocidade e indicadores de altas habilidades/superdotação. In: Congresso Brasileiro de Educação Especial, 7, 2016. São Carlos. Anais... São Carlos: Universidade Federal de São Carlos, 2016, p. 1-16.

MARTINS, Bárbara Amaral; CHACON, Miguel Claudio Moriel; ALMEIDA, Leandro da Silva. Altas habilidades/superdotação na formação de professores brasileiros e portugueses: um estudo comparativo entre os casos da UNESP e da UMinho. Educação em Revista, v. 36, p. 1-20, 2020.

MENDONÇA, Lurian Dionizio; RODRIGUES, Olga Maria Piazentin Rolim; CAPELLINI, Vera Lúcia Messias Fialho. Identificação inicial de alunos com altas habilidades ou superdotação: avaliação intelectual, de desempenho escolar e indicação pelos professores. Revista Educação Especial, Santa Maria, v. 30, n. 57, p. 203-218, jan./abr. 2017. Disponível em: https://periodicos.ufsm.br/educacaoespecial/article/view/24120. Acesso em: 13 fev. 2017.

MORAIS, Maria de Fátima; FLEITH, Denise de Sousa. Conceito e avaliação da criatividade. In: ALMEIDA, Leandro da Silva (coord.). Criatividade e pensamento crítico: conceito, avaliação e desenvolvimento. Braga: CERPSI, 2017, p. 19-44.

NAKANO, Tatiana de Cássia; PRIMI, Ricardo. Bateria de avaliação das altas habilidades/superdotação. 2012. Não publicada.

NAKANO, Tatiana de Cássia et al. Bateria para avaliação das altas habilidades/superdotação: análise dos itens via Teoria de Resposta ao Item. Estudos de Psicologia. Campinas, v. 32, n. 04, p. 729-741, out./dez. 2015.

NAKANO, Tatiana de Cássia et al. Investigación de la eficacia de una escala de evaluación de altas habilidades - versión profesor. Revista de Estudios y Experiencias en Educación, v. 15, n. 29, p. 83-94, dez. 2016.

NAKANO, Tatiana de Cássia; CAMPOS, Carolina Rosa; SANTOS, Maristela Volpe dos. Escala de avaliação de altas habilidades/superdotação. Estudos Interdisciplinares em Psicologia, Londrina, v. 7, n. 1, p. 103-123, jul. 2016. 
PÉREZ, Susana Graciela Pérez Barrera. Gasparzinho vai à escola: um estudo sobre as características do aluno com altas habilidades produtivo-criativo. Porto Alegre: PUC, 2004. Dissertação (Mestrado em Educação) - Programa de Pós-Graduação, Faculdade de Educação, Pontifícia Universidade Católica do Rio Grande do Sul, Porto Alegre, 2004.

PÉREZ, Susana Graciela Pérez Barrera; FREITAS, Soraia Napoleão. Encaminhamentos Pedagógicos com alunos com Altas Habilidades/Superdotação na Educação Básica: 0 cenário brasileiro. Educar em Revista, v. 41, p. 109-124, 2011.

PÉREZ, Susana Graciela Pérez Barrera; FREITAS, Soraia Napoleão. Manual de identificação de altas habilidades/superdotação. Guarapuava: Apprehendere, 2016.

PFEIFFER, Steven I.; JAROSEWICH, Tania. Gifted Rating Scales - Manual. San Antonio/TX: Pearson, 2003.

POCINHO, Margarida. Superdotação: conceitos e modelos de diagnóstico e intervenção psicoeducativa. Revista Brasileira de Educação Especial, Marília, v. 15, n. 01, p. 3-14, jan./abr. 2009.

PRIETO SÁNCHEZ, María Dolores; FERRANDO, Mercedes. New Horizons in the study of High Ability: Gifted and talented. Anales de psicología, v. 32, n. 03, p. 617-620, out./2016.

REIS, Sally M.; RENZULLI, Joseph S. Myth 1: The gifted and talented constitute one single homogeneous group and giftedness is a way of being that stays in the person over time and experiences. Gifted Child Quartely, lowa, v. 53, n. 4, p. 232-235, sept. 2009.

RENZULLI, Joseph S. What makes giftedness? Re-examining a definition. Phi Delta Kappa, [S.I.], v. 60, n. 3, p. 180-84, 261, nov. 1978.

RIBEIRO, Walquiria de Jesus. Evidências de validade de uma bateria para avaliação das altas habilidades/superdotação. Campinas: PUC, 2013. Dissertação (Mestrado em Psicologia) - Programa de Pós-Graduação, Centro de Ciências da Vida, Pontifícia Universidade Católica de Campinas, Campinas, 2013.

SÁNCHEZ ANEAS, Asela. Altas capacidades intelectuales: sobredotación y talentos: Detección, evalución, diagnóstico e intervención educativa y familiar. Formación Alcalá: Alcalá la Real, 2013.

SOUZA, Ana Cláudia de; ALEXANDRE, Neusa Maria Costa; GUIRARDELLO, Edinêis de Brito. Propriedades psicométricas na avaliação de instrumentos: avaliação da confiabilidade e da validade. Epidemiologia e Serviços de Saúde, Brasília, v. 26, n. 03, p. 649-659, jul./set. 2017.

ZAIA, Priscila; NAKANO, Tatiana de Cássia; PEIXOTO, Evandro Morais. Scale for Identification of Characteristics of Giftedness: Internal structure analysis. Estudos de Psicologia, Campinas, v. 35, n. 1, jan./mar. 2018. 
http://dx.doi.org/10.5902/1984686X34664

\section{Notas}

${ }^{1}$ Programa coordenado pelo Dr. Miguel Claudio Moriel Chacon, de 2011 a 2018, quando o programa foi extinto.

\section{Correspondência}

Bárbara Amaral Martins - Rua Eugênio Cunha, 444, Bairro Universitário, Corumbá, MS Brasil.

CEP: 79304-031

\section{(c) (1) (8)}

This work is licensed under a Creative Commons Attribution-NonCommercial 4.0 International (CC BY-NC 4.0) 